NASA Technical Memorandum 100737

\title{
Optimum Data Weighting and Error Calibration for Estimation of Gravitational Parameters
}

F. J. Lerch

July 1989

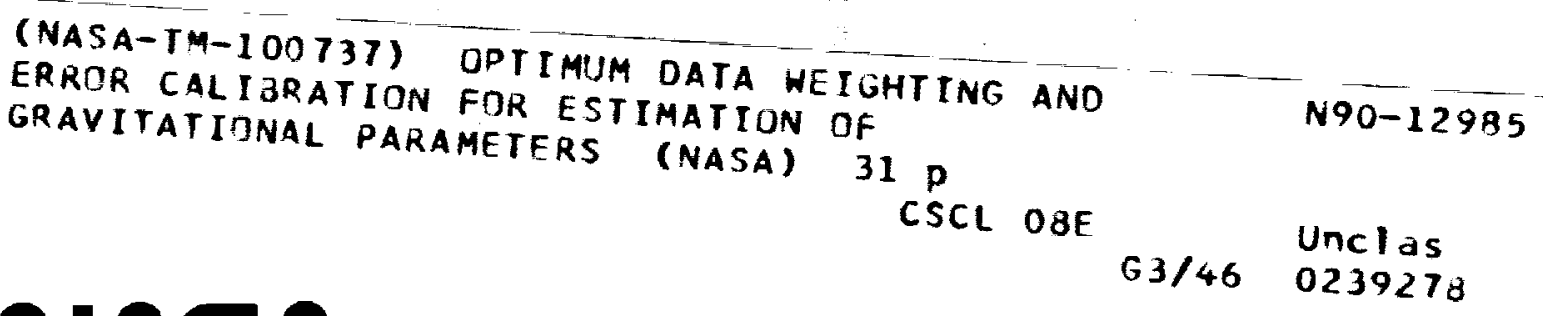


NASA Technical Memorandum 100737

\section{Optimum Data Weighting and Error Calibration for Estimation of Gravitational Parameters}

F. J. Lerch

NASA/ Goddard Space Flight Center

Greenbelt, Maryland

\section{N/SA}

National Aeronautics and

Space Administration

Goddard Space Flight Center

Greenbelt, Maryland 
-...

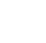




\section{PREFACE}

A new technique has been developed for the weighting of data from satellite tracking systems in order to obtain an optimum least squares solution and an error calibration for the solution parameters. Data sets from optical, electronic, and laser systems on 17 satellites in GEM-T1 (Goddard Earth Model, $36 \times 36$ spherical harmonic field) have been employed toward application of this technique for gravity field parameters. Also GEM-T2 (31 satellites) was recently computed as a direct application of the method and is summarized here. The method employs subset solutions of the data associated with the complete solution and uses an algorithm to adjust the data weights by requiring the differences of parameters between solutions to agree with their error estimates. With the adjusted weights the process provides for an automatic calibration of the error estimates for the solution parameters. The data weights derived are generally much smaller than corresponding weights obtained from nominal values of observation accuracy or residuals. Independent tests show significant improvement for solutions with optimal weighting as compared to the nominal weighting. The technique is general and may be applied to orbit parameters, station coordinates, or other parameters than the gravity model. 



\section{CONTENTS}

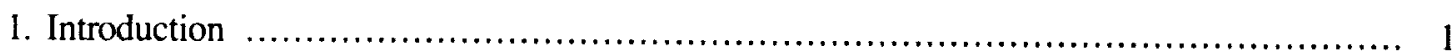

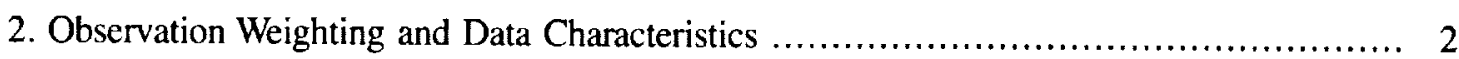

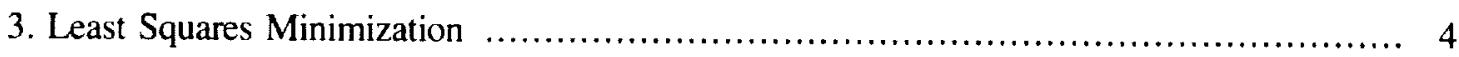

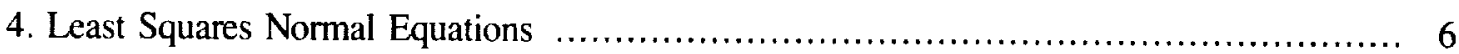

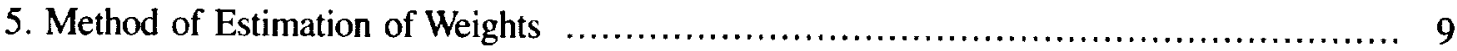

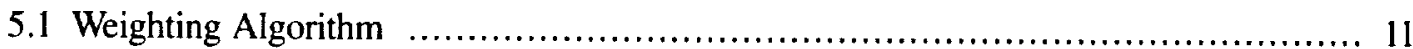

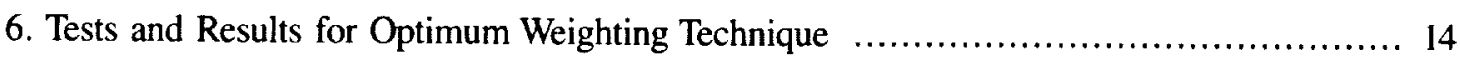

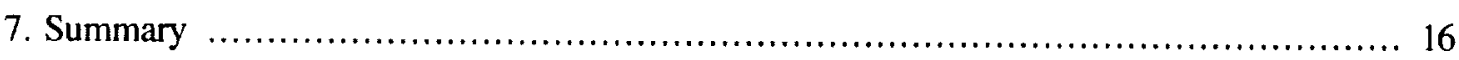

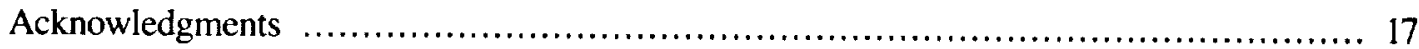

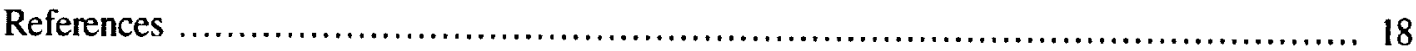

PRECEDING PAGE RLANE NOT FILMED

$\mathrm{v}$ 
. 
1. INTRODUCTION

The method of data weighting has been an outgrowth of a calibration process for the error estimation of gravitational models that have been derived from satellite data, Lerch et al. (1985 and 1988) and wagner and Lerch (1978). The principle of the new technique is to estimate the weighting of the data so as to produce realistic error estimates of the solution parameters from subset solutions of least squares normal equations. Application has generally been with use of a large set of satellites with inhomogeneous data from tracking systems of laser, electronic, and camera (optical) data. The gravity model of GEM-T1 (Marsh et al., 1988) using some 17 satellites has been tested with the new technique and the GEM-T2 (Marsh et al., 1989) solution with some 31 satellites has been derived with the new process of optimum weighting of the satellite data sets.

The accuracy estimation of the gravity model is particularly important for the TOPEX Project (1992 launch) for ocean application of its altimetry. It requires that the radial orbit error be accurate to better than $10 \mathrm{~cm}$ due to the uncertainty of the gravity field. Hence the estimation process for the errors, which are based upon the weights assigned to the data, must be reliable. The accuracy of the solutions, particularly the low degree field, is also important for the Lageos orbit. Accuracy is needed for the estimation of baseline motion of laser tracking sites at the centimeter-per-year level as part of the NASA Crustal Dynamics Project. 


\section{OBSERVATION WEIGHTING AND DATA CHARACTERISTICS}

Observations obtained from geodetic satellite tracking systems generally have precision levels, particularly laser systems, much better than the observation residuals obtained from satellite orbital arcs in post-fit analyses using the best models. This is true even though the orbital models employed were derived from the same satellite data and with the same arc lengths of several days. The problem here is that there are unmodeled systematic errors (biases) which need to be accounted for in the weighting system of the solution (Brown, 1988).

In Figure 1 an example of the characteristics of the residuals is shown for a pass of data from a typical laser tracking site. The precision error $\left(\sigma_{0}\right)$ of the laser data is generally small (centimeter level) as compared to the $\mathrm{rms}\left(\sigma_{t}\right)$ of the residuals for a satellite data set $t$. Values of $\sigma_{t}$ are given in Tables $1 \mathrm{~A}$ and $1 \mathrm{~B}$ (GEM-T1 and T2 data sets) for different satellite data types, and for laser systems, $o_{t}$ varies from $10 \mathrm{~cm}$ for Lageos orbits to over $50 \mathrm{~cm}$ on GEOS-1 orbital data in 1978.

Note in Figure 1 that the residuals of a tracking pass with noise removed fit very closely to a straight line as a function of a bias offsec $\left(b_{0}\right)$ and a timing error. The bias offset is the dominant part of the residuals. If the residuals were random with rms equal to $\sigma_{t}$ the weight per observation point should be

$$
w_{t}=1 / \sigma_{t}^{2}
$$

but with a constant of set $\left(b_{0}\right)$, say for $N=50$ points in a pass, the weight should be degraded by

$$
w_{t}=1 / N \sigma_{t}^{2}=.02 / \sigma_{t}^{2}
$$


The latter case is characteristic of our situation particularly for the high-precision laser data. The bias effects per pass tend to fluctuate randomly from pass to pass.

In general, for a given satellite data type $t$ we have

$$
w_{t}=f_{t} / \sigma_{t}^{2}
$$

where $o_{t}$ is the rms of residuals for the satellite data set and $f_{t}$ is a downweighting factor to account for the bias effects and the correlated effects of the residuals, particularly within the pass. The weighting technique will obtain $w_{t}$ directly. Note from Table $1 A$ (and $1 B$ ), $\hat{o}_{t}^{2}$ as well as $\sigma_{t}$ is given for each data type where

$$
w_{t}=1 / \hat{\sigma}_{t}^{2}
$$

hence

$$
f_{t}=\left(\sigma_{t} / \hat{\sigma}_{t}\right)^{2}
$$

which is approximately a constant

$$
f_{t} \simeq .01
$$

for the satellites with the laser data. In Table $1 \mathrm{~B}$ for the Starlette $\left({ }^{\prime} 86\right)$ and AJISAI laser data, $f_{t} \approx .002$ instead of .01 since the data rates were 5 times faster ( 1 per second as compared to 1 per 5 seconds), and hence $f_{t}$ counteracted the excess data. Note also for the optical systems, the factor $f_{t}$ is generally much larger than with the laser systems. This may be expected since the number of points per pass for optical data are fewer and the ratio of noise to bias is much larger than with the laser data. 
The method of solution is a modified least squares process which minimizes the sum $(Q)$ of signal and noise as follows:

$$
Q=\sum_{\ell, m} \frac{C_{\ell, m}^{2}+s_{l, m}^{2}}{\sigma_{\ell}^{2}}+\sum_{t} \sum_{\substack{i \\ i}} \frac{r_{i t}^{2}}{\sigma_{t}^{2}} f_{t}
$$

- where the signal is given by

$$
\begin{aligned}
& C_{\ell, m}, S_{\ell, m}: \begin{array}{l}
\text { spherical harmonics comprising the solution } \\
\text { coefficients; and }
\end{array} \\
& \sigma_{\ell}: \frac{1}{\sqrt{2}} \times \frac{10^{-5}}{\ell^{2}}
\end{aligned}
$$

- $\quad$ and the noise by

$$
\begin{aligned}
& r_{i t}: \begin{array}{l}
\text { observation residual (observed-computed) } \\
\text { for the ith observation of satellite } \\
\text { tracking data set (type) } t \text {; and }
\end{array} \\
& \sigma_{t}: \quad \begin{array}{l}
\text { rms of observation residuals (generally } \\
\text { significantly greater than a priori } \\
\text { data precision) }
\end{array} \\
& \mathrm{f}_{t}: \begin{array}{l}
\text { downweighting factor to compensate for unmodeled } \\
\text { error effects for each data type } t \text { (ideally } f=1 \text { for } \\
\text { pure noise). }
\end{array}
\end{aligned}
$$

The optimum weighting method estimates the combined weight directly, namely 


$$
w_{t}=f_{t} / \sigma_{t}^{2}
$$

When minimizing $Q$ above using the least squares method, the normal matrix equation and error covariance is obtained as follows:

$$
\begin{aligned}
& \mathrm{Nx}=\mathrm{R} \quad \begin{array}{l}
\text { are the normal equations, where } \mathrm{x} \text { is the } \\
\text { solution, } \mathrm{R} \text { is the vector of residuals, and }
\end{array} \\
& \mathrm{V}_{\mathrm{zz}}=\mathrm{N}^{-1}
\end{aligned} \begin{aligned}
& \text { is the approximate form for the variance- } \\
& \text { covariance error matrix which must be } \\
& \text { calibrated by adjusting the weighting. }
\end{aligned}
$$

The process of minimizing both signal (Kaula constraints) plus noise in (1) is also known as collocation by Moritz (1978). With the normal least squares approach (noise-only minimization) there is a problem of separability due to the strong correlation between many of the high degree coefficients. The absence of collocation (GEM-T1 without the Kaula constraint) results in excessively large power in the adjustment of the potential coefficients. Figure 2 illustrates the instability of the least-squares solution when collocation is not used. A satellite-derived gravity solution has been solved without collocation which is evaluated using a global set of independent gravity anomalies. An unrestricted high degree field performs poorly due to excessively large adjustment in the coefficients which is normally circumvented in the standard least-squares method by solving for a smaller sized field. Unfortunately, by restricting the size of the field, one also is requiring the higher degree terms above the field limits to be constrained absolutely to zero. Figure 2 also shows the disadvantage of this approach where the smaller sized field (PGS-3067) contains aliasing in its coefficients and does not perform well. (The abbreviation PGS stands for Preliminary Gravity Solution.) The aliasing signal sensed in the data above the field limits is absorbed into the adjustment of the lower degree coefficients. The best approach is seen with the least squares collocation (or constrained) solution, GEM-T1, with a complete solution of a $36 \times 36$ field in harmonics. 
4. LEAST SQUARES NORMAL EQUATIONS

In matrix form the observation equation is given by, assuming linearity,

$$
\begin{aligned}
0-C & =r=r_{0}-A x \\
x & =X-X_{R}
\end{aligned}
$$

where

$$
\begin{aligned}
& r=0-C \ldots \text { residual, observation ( } 0 \text { ) minus computed value (C) } \\
& \text { from solution } \\
& x=X-X_{R}-- \text { adjustment of solution }(X) \text { from reference value } \\
& \left(X_{R}\right) \text { (for error analysis } X_{R} \equiv X(\text { true)) } \\
& \text { A -.- matrix of partials evaluated at } X=X_{R} \\
& r_{0} \quad-- \text { residuals based upon a priori value } X_{R} \text {. }
\end{aligned}
$$

For the gravity field, the linearity of perturbations may be seen for the spectrum of harmonics in Kaula (1966). The weighted normal equations are where $W$ is a diagonal weight matrix (Lawson and Hanson, 1974) --

$$
A^{T} \mathrm{Wr}=0
$$

then from (3)

$$
A^{T} \text { WAx }=A^{T} \text { Wr }_{0} \text {. }
$$

For error analysis it is convenient to let the reference value 


$$
X_{R}=X(\text { true })
$$

then from (3), $x$ is the error in the solution $x$, namely

$$
x=x-x(\text { true })
$$

Hence (4) becomes

$$
A^{T} W A x=A^{T} \text { We }
$$

where

$$
\begin{aligned}
e \equiv r_{0} & =0-C_{R} \\
& =0-C(\text { true })
\end{aligned}
$$

represents the errors due to all unmodeled systematic effects including random noise but excluding errors in the adjusted parameters. Instead, these are the errors in $x$ given by the solution to (5). Our solutions will be represented by the form (5) as we are interested in the difference between two solutions, $x$ and $\hat{x}$, namely

$$
\begin{aligned}
x-x & =[X-X(\text { true })]-[\hat{X}-X(\text { true })] \\
& =X-\hat{X} .
\end{aligned}
$$

The normal matrices for (5) are written compactly as

$$
\mathrm{Nx}=\mathrm{R}
$$

where 


$$
\begin{aligned}
& N=A^{T} \text { WA } \\
& R=A^{T} \text { We. }
\end{aligned}
$$

The normal matrices for each data subset $t$ will be given as

$$
\begin{aligned}
& w_{t} N_{t}=w_{t} A_{t}^{T} A_{t} \\
& w_{t} R_{t}=w_{t} A_{t}^{T} e_{t}
\end{aligned}
$$

where $t=0$ is a special case which corresponds to the signal constraints where the weight is fixed. 


\section{METHOD OF ESTIMATION OF WEIGHTS}

The technique for estimating $w_{t}$ for each data set $t$ is based upon a complete solution ( $S$ ) with all the data and a subset solution $\left(S_{t}\right)$ where data set $t$ is removed. Let the normal equations for the complete solution $x$ and the subset solution $x_{t}$ be given as in (7), namely

$$
\begin{aligned}
& N x=R \\
& \bar{N} x_{t}=\bar{R}
\end{aligned}
$$

where from (7)

$$
\begin{array}{ll}
\bar{N}=\sum_{j \neq t} w_{j} N_{j} & \bar{R}=\sum_{j \neq t} w_{j} R_{j} \\
N=\bar{N}+w_{t} N_{t} & R=\bar{R}+w_{t} R_{t} .
\end{array}
$$

The covariance (variance-covariance) matrices (V) for the errors $x$ and $x_{t}$ are obtained as

$$
\begin{aligned}
& V(x)=N^{-1} \equiv E\left(x x^{T}\right) \\
& V\left(x_{t}\right)=\bar{N}^{-1} \equiv E\left(x_{t} x_{t}^{T}\right) .
\end{aligned}
$$

As in (6),

$$
\begin{aligned}
x_{t}-x & =\left[x_{t}-x(\text { true })\right]-[x-x(\text { true })] \\
& =x_{t}-x .
\end{aligned}
$$

The covariance of the difference between the solutions is 


$$
\begin{aligned}
V\left(x_{t}-x\right)=E\left(x_{t}-x\right)\left(x_{t}-x\right)^{T} \\
=V\left(x_{t}\right)-2 E\left(x_{t} x^{T}\right)-V(x) \\
=V\left(x_{t}\right)-V(x)
\end{aligned}
$$

where as shown below

$$
E\left(x_{t} x^{T}\right)=V(x)
$$

From (9),

$$
E\left(x_{t} x^{T}\right)=\bar{N}^{-1} E\left(\bar{R} R^{T}\right) N^{-1}
$$

From (10) and (11),

$$
\begin{aligned}
E\left(\bar{R} R^{T}\right) & =E\left[\bar{R}\left(\bar{R}+w_{t} R_{t}\right)^{T}\right] \\
& =E\left(\bar{R} \bar{R}^{T}\right)=\bar{N} V\left(x_{t}\right) \bar{N} \\
& =\bar{N}
\end{aligned}
$$

since

$$
E\left(\bar{R} R_{t}^{T}\right)=0
$$

The latter result is true as from (10) the data set $t$ is excluded from the subset solution, making $\bar{R}$ and $R_{t}$ independent. Hence (14) results by substituting (16) into (15) and using (11). 


\subsection{WEIGHT ING ALGORITHM}

Using just the gravity parameters in $\left(X_{t}-X\right)$ the weighting algorithm is given by the calibration factor $k_{t}$ obtained from

$$
\left(x_{t}-x\right)^{T}\left(x_{t}-x\right)=\left(x_{t}-x\right)^{T}\left(x_{t}-x\right)=k_{t} \text { TR } v\left(x_{t}-x\right)
$$

where TR denotes the trace of the matrix and where from (9) through

$$
\begin{aligned}
x_{t}-x & =\bar{N}^{-1} R-N^{-1} R=x_{t}-X \\
\bar{N} & =\sum_{j \neq t} w_{j} N_{j} \\
N & =\bar{N}+w_{t} N_{t} \\
\bar{R} & =\sum_{j \neq t} w_{j} R_{j} \\
R & =\bar{R}+w_{t} R_{t} \\
V\left(x_{t}-x\right) & =\bar{N}^{-1}-N=V\left(x_{t}\right)-V(x) .
\end{aligned}
$$

Since $k_{t}$ scales the error variances it will be inversely proportional for scaling the weight $w_{t}$ to obtain the adjusted weight $w_{t}^{\prime}$, namely

$$
w_{t}^{-}=w_{t} / k_{t} \text {. }
$$

This latter result will be derived more directly below. By iterating on the solutions $x_{t}$ for each data set $t$ and the complete solution $x$ for all data sets until

$$
k_{t}=1
$$


for each $t$, the weights by (22) will then converge and the error estimates will automatically be calibrated from (17).

Results are given below to show how the weights and associated calibration factors converge. Because of the extensive computations for a large number of data sets a reasonable set of a priori values for the weights should be available for their refinement in the optimization process.

The gravity parameters of spherical harmonic coefficients are calibrated as a set by (17). Calibrations $\left(k_{t}\right)$ are also given by subsets of spectral components from the harmonics of degree $\ell$ and order $m$. For all satellite data sets $t$ (Lerch et al., 1988) relatively little variation is seen in the spectral calibrations.

\subsubsection{Weighting Ad justment}

The relation (18) for the weighting adjustment

$$
w_{t}^{\prime}=w_{t} / k_{t}
$$

is derived from use of (17) through (21). It is assumed that the data set $t$ does not significantly change the solutions $x$ and $x_{t}$ beyond first order effects as follows:

$$
\begin{aligned}
V\left(x_{t}-x\right) & =\bar{N}^{-1}-N^{-1}=\bar{N}^{-1}-\left(\bar{N}+w_{t} N_{t}\right)^{-1} \\
& =\bar{N}^{-1}-\left(I+w_{t} N_{t}\right)^{-1} \bar{N}^{-1} \\
& =w_{t} \bar{N}^{-1} N_{t} \bar{N}^{-1} .
\end{aligned}
$$

To the same approximation 


$$
\begin{aligned}
& x_{t}-x \approx w_{t} \bar{N}^{-1} R_{t} \\
& E\left(x_{t}-x\right)\left(x_{t}-x\right)^{T} \approx w_{t}^{2} \bar{N}^{-1} E\left(R_{t} R_{t}^{T}\right) \bar{N}^{-1} .
\end{aligned}
$$

From (8),

$$
\begin{aligned}
E\left(R_{t} R_{t}^{T}\right) & =A_{t}^{T} E\left(e_{t} e_{t}^{T}\right) A_{t} \\
& =\sigma_{t}^{2} N_{t} \\
& =N_{t} / w_{t}
\end{aligned}
$$

where $\hat{\sigma}_{t}$ accounts for the unmodeled systematic effects in $e_{t}$ and the corresponding weighting effect is given as

$$
w_{t}^{\prime}=\frac{1}{\sigma_{t}^{2}}=f_{t} / \sigma_{t}^{2} \text {. }
$$

Using (23) and (25), then (24) becomes

$$
E\left(x_{t}-x\right)\left(x_{t}-x\right)^{T}=\frac{w_{t}}{w_{t}^{\prime}} V\left(x_{t}-x\right)
$$

From (26) and (17)

$$
k_{t}=w_{t} / w_{t}^{\prime}
$$

which gives the result (22). 


\section{TESTS AND RESULTS FOR OPTIMUM WEIGHTING TECHNIQUE}

Sample tests of the weighting algorithm (22) were made using GEM-T1 plus additional data sets for several satellite data types of laser, optical, and electronic data. Results are given in Table 2 which show that the algorithm nearly converges in one step from the a priori starting weights. Plots of $w_{t}$ vs $k_{t}$ from (17) show a strong linear relationship from the origin $\left(w_{t}=k_{t}=0\right)$. Hence

$$
\frac{W^{\prime}}{k^{\prime}}=\frac{W}{k}
$$

and by setting $k^{-}=1$ for calibration the adjusted weight $w^{-}$should nearly converge from (22).

The above tests were made in preparing the weights for additional data sets to GEM-T1 that were combined for the GEM-T2 model. The convergence of these weights for GEM-T2 is shown in Table 3 . In addition to the optimum weights the technique provides an automatic calibration of the error estimates based upon the satellite data types $t$ since each of the $k_{t}$ from (17) is required to converge to 1.

The data weights in GEM-T1 were derived primarily by requiring the weight for each data type $t$ to give the best overall agreement with independent mean gravity anomalies (Rapp, 1986) and with the satellite observation residuals on selected test arcs. The calibration factors $\left(k_{t}{ }^{1 / 2}\right)$ for several of the major data types (Lerch et al., 1988) are given in Table 4 which show that the weights converge $\left(k_{t} \simeq 1\right)$ except for the Lageos laser data. However, several additional tests were made in Table 4 for the calibration factor using independent data from Seasat altimetry (Rapp, 1986) and surface gravity data (Pavlis, 1988). All of the latter tests show good calibration of the error estimates, indicating optimum weighting was closely achieved. The last test deliberately increased the weighting for a subset of laser data by a 
factor of $10 \mathrm{giving}$ a value $k_{t}=(2.75)^{2}$. From (22) the adjusted weight should be reduced by a factor of $1 / k_{t}$ which would nearly recover the original weight in one step of the iteration process. The gravity model with the increased weight naturally gives smaller error estimates but it also gave significantly worse agreement with independent surface gravity anomalies. 


\section{SUMMARY}

The optimum weighting technique was shown to be important in the weighting of satellite data, particularly precise laser data where unmodeled systematic effects require a significant downweighting factor as shown in Table 1. The method of weighting was shown in section 5.2 to provide realistic error estimates for GEM-T1 and-T2. These models were calibrated using subset solutions based not only on data employed in their solutions but also upon independent data from altimetry and gravimetry. Because of the important application of the gravity model to ocean altimetry in the Topex Project, the gravity model errors were projected on the radial component of the TOPEX orbit and the result gave $10 \mathrm{~cm}$ for GEM-T2 which nearly meets the goal of the gravity model.

It was also shown in Section 5.2 that the model with the increased weight on the data over the optimum weighting gave much poorer agreement with independent surface gravity anomalies. The optimum weighting technique based upon the mathematical formulae is general and may be applied to other than gravitational parameters such as station coordinates and, in particular, orbit parameters where knowledge of accuracy estimation and refined solutions are needed. 


\section{ACKNOWLEDGMENTS}

I wish to express my sincere thanks to Girish Patel of STX Corporation for his analysis and computation of the GEM-T1 and-T2 data weights and calibrations of this report. 
REFERENCES

Brown, R.D., Characterization of the GEOS-1 Laser Ranging Residuals (1976-1980), STX Contract Report 8801, Oct. 1988.

Kaula, W.M., Theory of Satellite Geodesy, Blaisdell Press, Waltham, Mass., 1966.

Lawson, C.L. and R.J. Hanson, Solving Least Squares Problems, PrenticeHall, Englewood Cliffs, New Jersey, 1974.

Lerch, F.J., Klosko, S.M., Wagner, C.A. and Patel, G.B., "On the Accuracy of Recent Goddard Gravity Models," J. Geophys. Res., 90, (B11), pp. 9312-9334, 1985.

Lerch, F.J., J.G. Marsh, S.M. Klosko, E.C. Pavlis, G.B. Patel, D.S. Chinn and C.A. Wagner, "An Improved Error Assessment for the GEM-T1 Gravitational Model," NASA TM 100713, 1988.

Marsh, J.G., F.J. Lerch, B.H. Putney, D.C. Christodoulidis, D.E. Smith, T.L. Felsentreger, B.V. Sanchez, S.M. Klosko, E.C. Pavlis, T.V. Martin, J.W. Robbins, R.G. Williamson, O.L. Colombo, D.D. Rowlands, W.F. Eddy, N.L. Chandler, K.E. Rachlin, G.B. Patel, S. Bhati, and D.S. Chinn, "A New Gravitational Model for the Earth from Satellite Tracking Data: GEM-T1," J. of Geophys. Res., 93, $6169-6215,1988$.

Marsh, J.G., F.J. Lerch, B.H. Putney, D.E. Smith, T.L. Felsentreger, B.V. Sanchez, S.M. Klosko, E.C. Pavlis, T.V. Martin, J.W. Robbins, R.G. Williamson, O.L. Colombo, D.D. Rowlands, W.F. Eddy, N.L. Chandler, K.E. Rachlin, G.B. Patel, S. Bhati, and D.S. Chinn, "A New Gravitational Model for the Earth from Satellite Tracking Data: GEM-T2," in Print, 1989: 
Moritz, H., "Least Squares Collocation," Rev. Geophys., 16, 421-430, 1978.

Pavlis, N.K., "Modeling and Estimation of a Low Degree Geopotential Model from Terrestrial Gravity Data," Report No. 386, Department of Geodetic Science, OSU, March 1988.

Rapp, R.H., "Gravity Anomalies and Sea Surface Heights Derived from Combined GEOS-3/SEASAT Altimeter Data Set, J. Geophys. Res. 91, E5, $4867-4876,1986$.

Wagner, C.A. and Lerch, F.J., "The Accuracy of Geopotential Models," Planet. Space Sci., Vol. 26, pp. 1081-1140, 1978. 
TABLE 1A

SATELLITE DATA IN GEM-T1

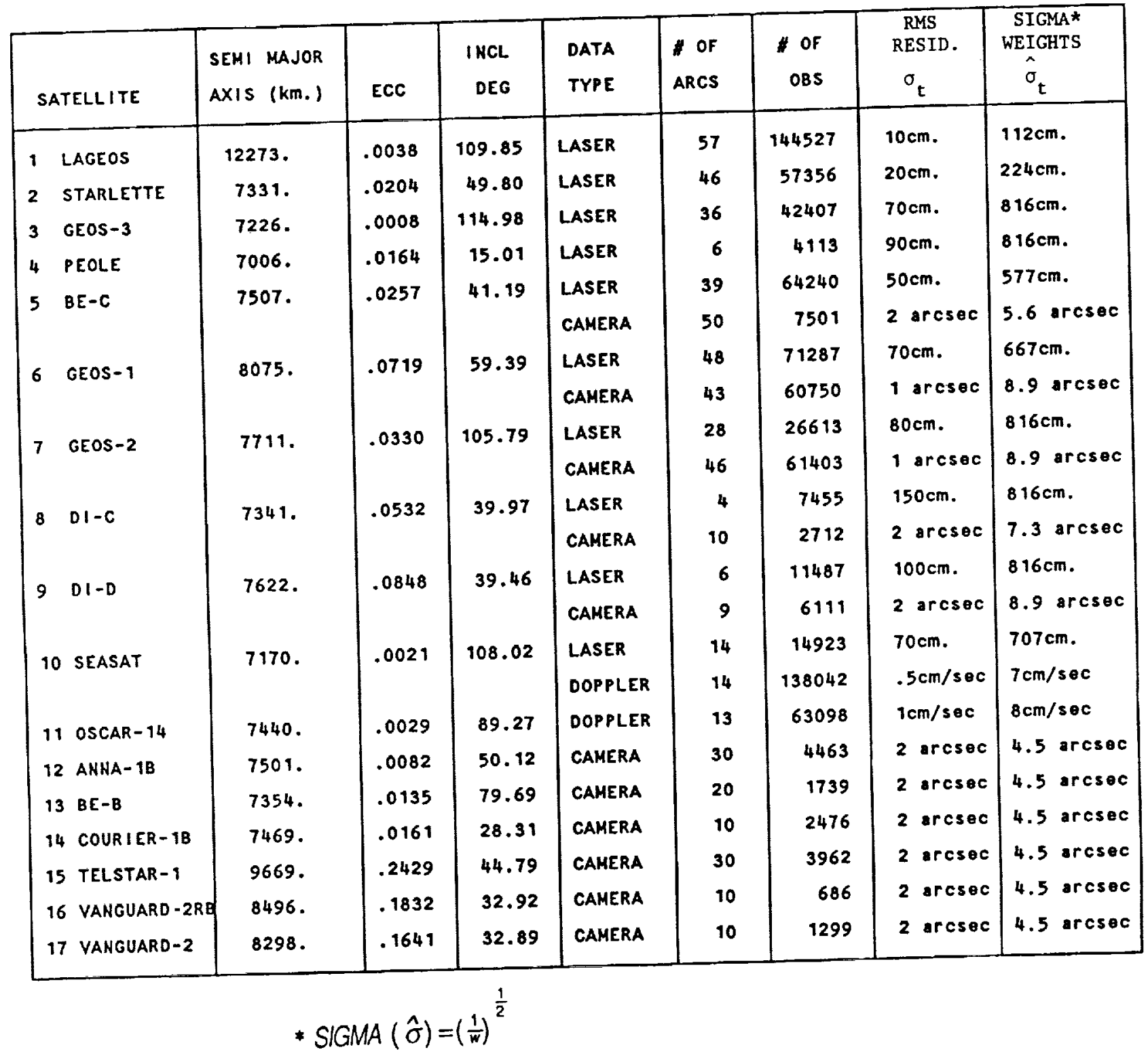


TABLE 1B

NEW SATELLITE DATA IN GEM-T2 IN ADDITION TO GEM-T1

\begin{tabular}{|c|c|c|c|c|c|c|c|c|}
\hline SATELLITE & $\begin{array}{l}\text { SEMI MANOR } \\
\text { AXIS }(\mathrm{km}) \text {. }\end{array}$ & $E C C$ & $\begin{array}{l}\text { INCL } \\
\text { DEG }\end{array}$ & $\begin{array}{l}\text { DATA } \\
\text { IYPE }\end{array}$ & $\begin{array}{l}\text { \#OF } \\
\text { ARCS }\end{array}$ & $\begin{array}{l}\text { \#OF } \\
\text { OBS }\end{array}$ & $\begin{array}{c}\sigma_{t} \\
\text { RMS } \\
\text { RESID }\end{array}$ & $\begin{array}{c}\hat{\sigma}_{t} \\
\text { SIGMA* } \\
\text { WEIGHTS }\end{array}$ \\
\hline $\begin{array}{c}\text { LAGEOS } \\
' 84, ' 85, ' 86, ' 87\end{array}$ & 12273 & .0038 & 109.85 & LASER & 29 & 134093 & $10 \mathrm{~cm}$. & $112 \mathrm{~cm}$. \\
\hline $\begin{array}{c}\text { STARLETTE } \\
: 83,84\end{array}$ & 7331 & .024 & 49.80 & LASER & 38 & 40041 & $20 \mathrm{~cm}$. & $224 \mathrm{~cm}$. \\
\hline$\underset{186}{\text { STARLETTE }}$ & & & & LASER & 73 & 411102 & $20 \mathrm{~cm}$ & $500 \mathrm{~cm}$ \\
\hline AJISAI & 1500 & .0006 & 50.0 & LASER & 36 & 156021 & $16 \mathrm{~cm}$. & $316 \mathrm{~cm}$. \\
\hline GEOS-1 '80 & 8075 & .0719 & 59.39 & LASER & 30 & 54129 & $32 \mathrm{~cm}$. & $258 \mathrm{~cm}$. \\
\hline GEOS-3 '80 & 7226 & .0008 & 114.98 & LASER & 50 & 54526 & $25 \mathrm{~cm}$. & $224 \mathrm{~cm}$. \\
\hline $\begin{array}{c}\text { GEOS-3 } \\
\text { GEOS-3:ATS } \\
75: 76\end{array}$ & & & & $\begin{array}{l}\text { LASER } \\
\text { SST }\end{array}$ & $\begin{array}{r}26 \\
9\end{array}$ & $\begin{array}{l}17027 \\
19074\end{array}$ & $\begin{array}{l}70 \mathrm{~cm} . \\
.4 \mathrm{~cm} / \mathrm{sec}\end{array}$ & $\begin{array}{c}816 \mathrm{~cm} . \\
7.1 \mathrm{~cm} / \mathrm{sec}\end{array}$ \\
\hline $\begin{array}{c}\text { GEOS-3:ATS } \\
77.78 .79\end{array}$ & & & & SST & 17 & 8326 & $.2 \mathrm{~cm} / \mathrm{sec}$ & $3.2 \mathrm{~cm} / \mathrm{sec}$ \\
\hline NOVA & 1170 & .0011 & 89.96 & DOPPLER & 16 & 73238 & $.4 \mathrm{~cm} / \mathrm{sec}$ & $2.6 \mathrm{~cm} / \mathrm{sec}$ \\
\hline LANDSAT-1 & 900 & .0012 & 99.12 & DOPPLER & 10 & 26426 & $1.5 \mathrm{~cm} / \mathrm{sec}$ & $10.5 \mathrm{~cm} / \mathrm{sec}$ \\
\hline GEOSAT & 800 & .0008 & 108.0 & DOPPLER & 13 & 549141 & $1.3 \mathrm{~cm} / \mathrm{sec}$ & $4.5 \mathrm{~cm} / \mathrm{sec}$ \\
\hline OVI-2 & 8317 & .0184 & 144.27 & CAMERA & 4 & 973 & 2 arcsec & $5.8 \operatorname{arcsec}$ \\
\hline ECHO-1RB & 7966 & .0118 & 47.21 & CAMERA & 32 & 4482 & $2 \operatorname{arcsec}$ & $8.2 \operatorname{arcsec}$ \\
\hline SECOR-5 & 8151 & .0793 & 69.22 & CAMERA & 13 & 726 & $2 \operatorname{arcsec}$ & $5.8 \operatorname{arcsec}$ \\
\hline INJUN-1 & 7316 & .0079 & 66.82 & CAMERA & 44 & 3310 & 2 arcsec & $8.2 \operatorname{arcsec}$ \\
\hline TRANSIT-4A & 7322 & .0076 & 66.82 & CAMERA & 50 & 3832 & 2 arcsec & $8.2 \operatorname{arcsec}$ \\
\hline $5 \mathrm{BN}-2$ & 7462 & .0058 & 89.95 & CAMERA & 17 & 820 & $2 \operatorname{arcsec}$ & 8.2 arcsec \\
\hline OGO-2 & 7341 & .0752 & 87.37 & CAMERA & 16 & 1207 & 2 arcsec & $8.2 \operatorname{arcsec}$ \\
\hline OSCAR-7 & 7411 & .0224 & 89.70 & CAMERA & 4 & 1862 & 2 arcsec & 5.8 arcsec \\
\hline MIDAS-4 & 9995 & .0112 & 95.83 & CAMERA & 50 & 31779 & 2 arcsec & 8.2 arcsec \\
\hline
\end{tabular}


TABLE 2

TEST FOR OPTIMUM WEIGHTING TECHNIQUE WITH GEM-T1 AS SUBSET SOLUTION (TWO ITERATIONS)

$$
w_{t}^{-}=\frac{w_{t}}{k_{t}}
$$

$\frac{\text { GEM-T } 1+}{1980 \text { GEOS-1 LASER }}$

STARLETTE LASER

(73 1986 ARCS)

NOVA DOPPLER

( 16 ARCS)

9 NEW OPTICAL SATS.

(230 ARCS)

LANDSAT S-BAND

(10 ARCS) $\underline{t}$

.49

.88

.46

.78

1.60

1.02

3.2

.97

.60

.98

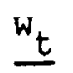

.05

.10

.020

.043

.1

.062

.2

.063

.0025

.0042 $w_{t}^{-}$

.10

.11

.043

.055

.062

.061

.063

.065

.0042

.0043 
TABLE 3

DATA WEIGHTS AND CALIBRATION OF GEM-T2

\begin{tabular}{|c|c|c|c|c|c|c|c|c|}
\hline $\begin{array}{l}\text { SUBSET } \\
\text { SOUTION } \\
\text { DATASEI }\end{array}$ & $\begin{array}{c}\text { PGS3429 } \\
\text { CALBRATION } \\
\text { EACTORS }\end{array}$ & $\begin{array}{l}\text { PGS3429 } \\
\text { WEIGHIS }\end{array}$ & $\begin{array}{l}\text { PGS3454 } \\
\text { WEIGHTS }\end{array}$ & $\begin{array}{l}\text { PGS3454 } \\
\text { CALBRATION } \\
\text { EACTORS }\end{array}$ & $\begin{array}{l}\text { PGS3480 } \\
\text { WEIGHIS }\end{array}$ & $\begin{array}{l}\text { PGS3480 } \\
\text { CALBRATION } \\
\text { EACTOBS }\end{array}$ & $\begin{array}{r}\text { GEM-T2 } \\
\text { WEGHTS }\end{array}$ & $\begin{array}{c}\text { GEM-T2 } \\
\text { CALBRATION } \\
\text { EACTORS }\end{array}$ \\
\hline A.JISAI & 1.28 & .4 & $3^{(1)}$ & 1.21 & 2 & 1.29 & 1 & .79 \\
\hline LAGEOS & 1.29 & .8 & .8 & 1.00 & .8 & 1.11 & .8 & .87 \\
\hline STARLETTE & 1.04 & $.2, .2, .04$ & $.2, .2, .04$ & 1.01 & $.2, .2, .04$ & .96 & $.2, .2, .04$ & .96 \\
\hline 4-LASER" & 1.02 & .015 & .015 & 1.00 & .015 & .96 & .015 & 1.01 \\
\hline GESAT & .59 & .01 & .015 & .66 & 035 & .75 & .05 & .81 \\
\hline $\begin{array}{l}\text { GEOS-3:ATS } \\
\text { LASER,SST }\end{array}$ & .68 & $.015, .1, .02$ & $.015,05, .02$ & .73 & $.015,1.02$ & .66 & $.015, .1, .02$ & $.66^{(3)}$ \\
\hline NOVA & .82 & .07 & .075 & .83 & 1 & .83 & 15 & .90 \\
\hline LANDSAT & .90 & .0075 & .0075 & .90 & .009 & .92 & .009 & .92 \\
\hline $\begin{array}{c}1980 \text { GEOS-3 } \\
\text { LASER }\end{array}$ & .86 & .1 & 15 & .91 & 2 & .97 & .2 & .96 \\
\hline $\begin{array}{l}1980 \text { GEOS-1 } \\
\text { LASER }\end{array}$ & .87 & .1 & 15 & .97 & .15 & .99 & .15 & 1.05 \\
\hline OPTICAL" & .95 & $.05, .06$ & $.05, .06$ & .95 & $.05 . .06$ & .94 & .05 .06 & .92 \\
\hline SEASAT & & .02 & .02 & 1.02 & .02 & .97 & .02 & .94 \\
\hline OSCAR & & .015 & .015 & 1.47 & .007 & .95 & .007 & 1.13 \\
\hline 3-LASER & & .015 & .015 & .82 & .015 & .83 & .02 & .87 \\
\hline
\end{tabular}

1. UNDERUNED WEIGHTS ARE THE ADJUSTED ONES IN THE ITERATED SOLUTIONS

2. CALUBRATION FACTORS ARE CONSERVATIVE BUT SUFFICIENTLY CONVERGED

3. ATS SST WEIGHT DEUBERATELY UNDERWEIGHTED BASED UPON COMPARISION WITH SEASAT ALTIMETER ANOMALES

- 4-LASER dataset is laser data from GEOS-1, GEOS-2, GEOS-3 and BE-C satellites 3-LASER datasel is laser data from DI-C, DI-D, and PEOLE satellites

OPTICAL dataset is the camera data from 20 satellites shown in TABLE $1 A$ and 1B 
TABLE 4

\title{
SUMMARY OF RESULTS FOR ERROR CALIBRATION
}

\author{
FACTOR \\ GEM-T1 vs. GEM-T1 minus DATA SUBSET

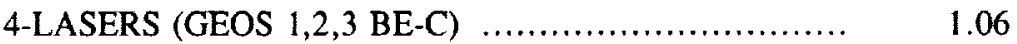

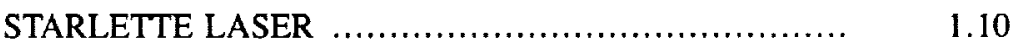

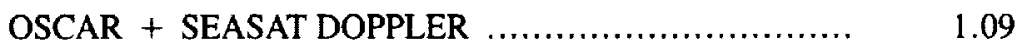 \\ OPTICAL (11 SATS) ….................................. \\ LAGEOS LASER ….................................... $1 . \overline{45}$ \\ GEM-T1 vs. GEM-T1 + SURFACE GRAVITY …......... 0.95 \\ GEM-T1 vs. GEM-T1 + SURFACE GRAVITY + \\ SEASAT ALTIMETER .................................... 0.94 \\ GEM-T1 vs. SURFACE GRAVITY + SEASAT \\ ALTIMETER ........................................... 0.99 \\ GEM-T 1 minus LAGEOS vs. LAGEOS + SURFACE \\ GRAVITY + SEASAT ALTIMETER .................. 0.95 \\ Weighting Factor $\mathrm{f}=0.2$ \\ 10 TIMES DATA WEIGHT OF GEM-T1 \\ GEM-T1 vs. GEM-T1 minus 4-LASERS

CALIBRATION 


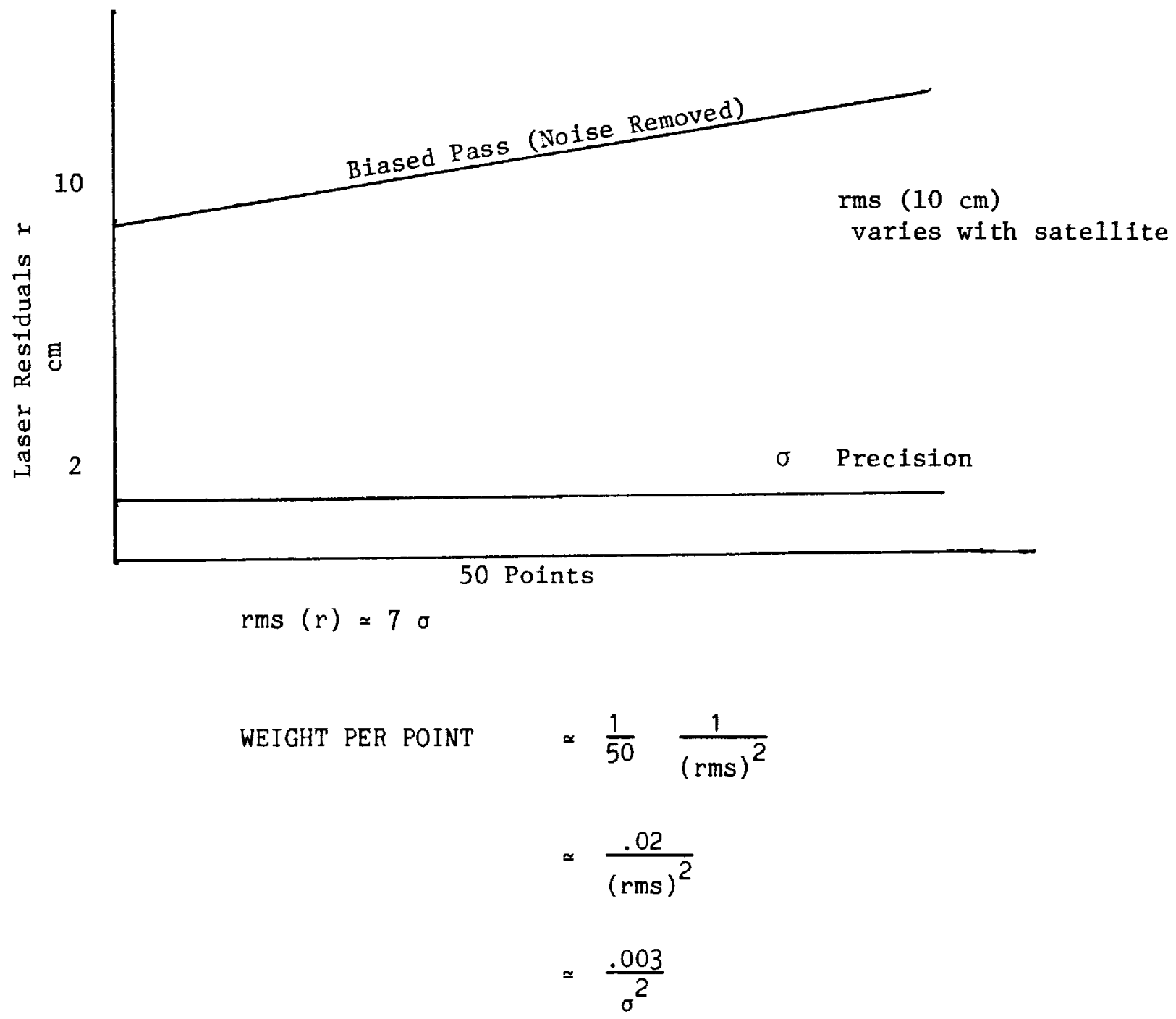

Figure 1. Characteristics of a Pass of Orbital Laser Residuals at a Tracking Site in Post Fit Analysis 


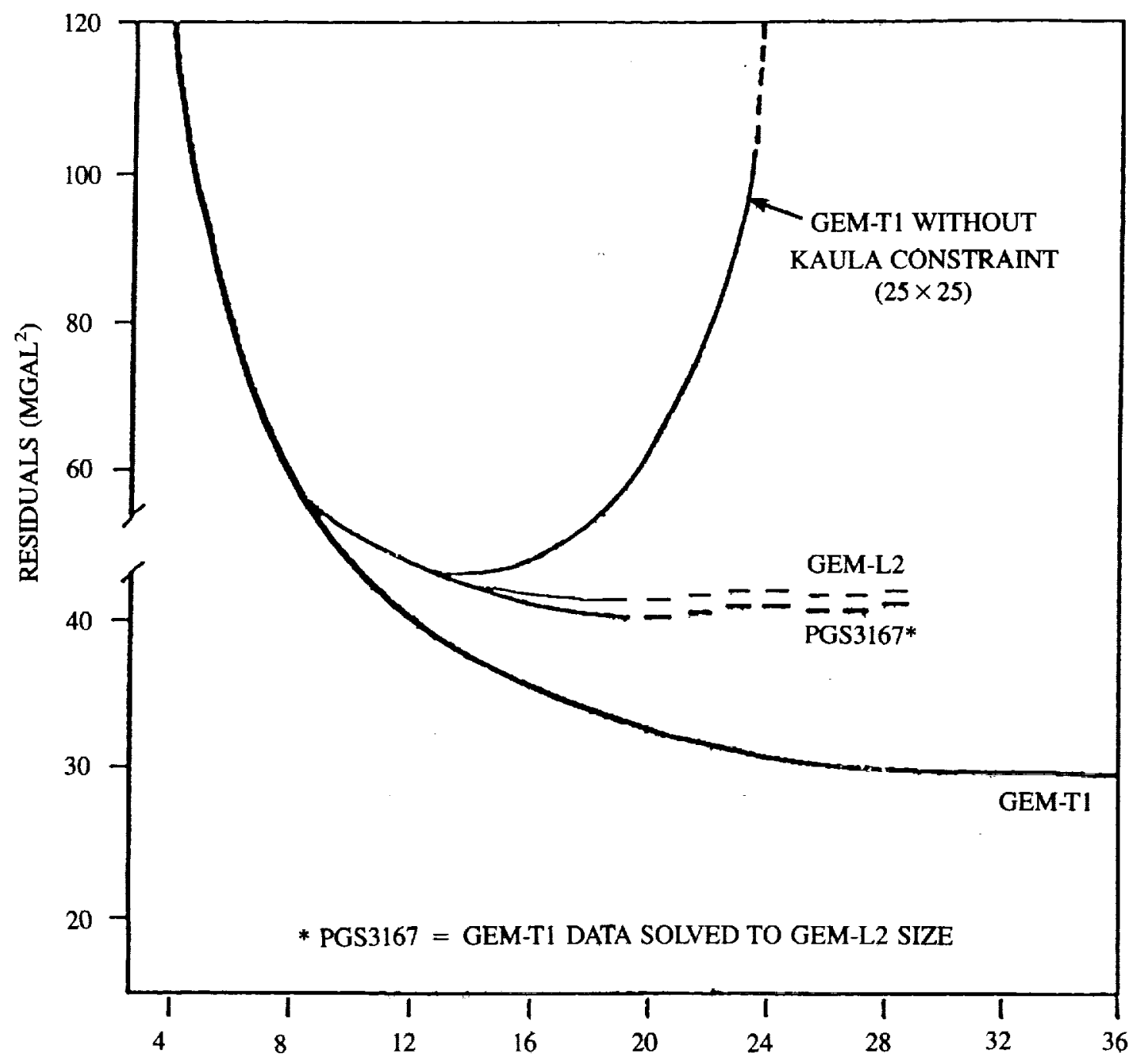

DEGREE TRUNCATION IN HARMONICS

Models show three modes of solution. The $25 \times 25$ field solves GEM-T1 tracking data without the Kaula constraint showing misclosure for high-degree terms. PGS-3167 solves GEM-T1 data (with Kaula constraint) to the GEM-L2 size field $(20 \times 20)$, showing no improvement over our previous model. GEM-T1 uses the Kaula constraint with a high-degree field $(36 \times 36)$ and is free of the above problems.

Figure 2. Gravity Model Comparison With 1114 $5^{\circ} \times 5^{\circ}$ SEASAT Gravity Anomalies 



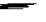

$=$ -

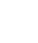




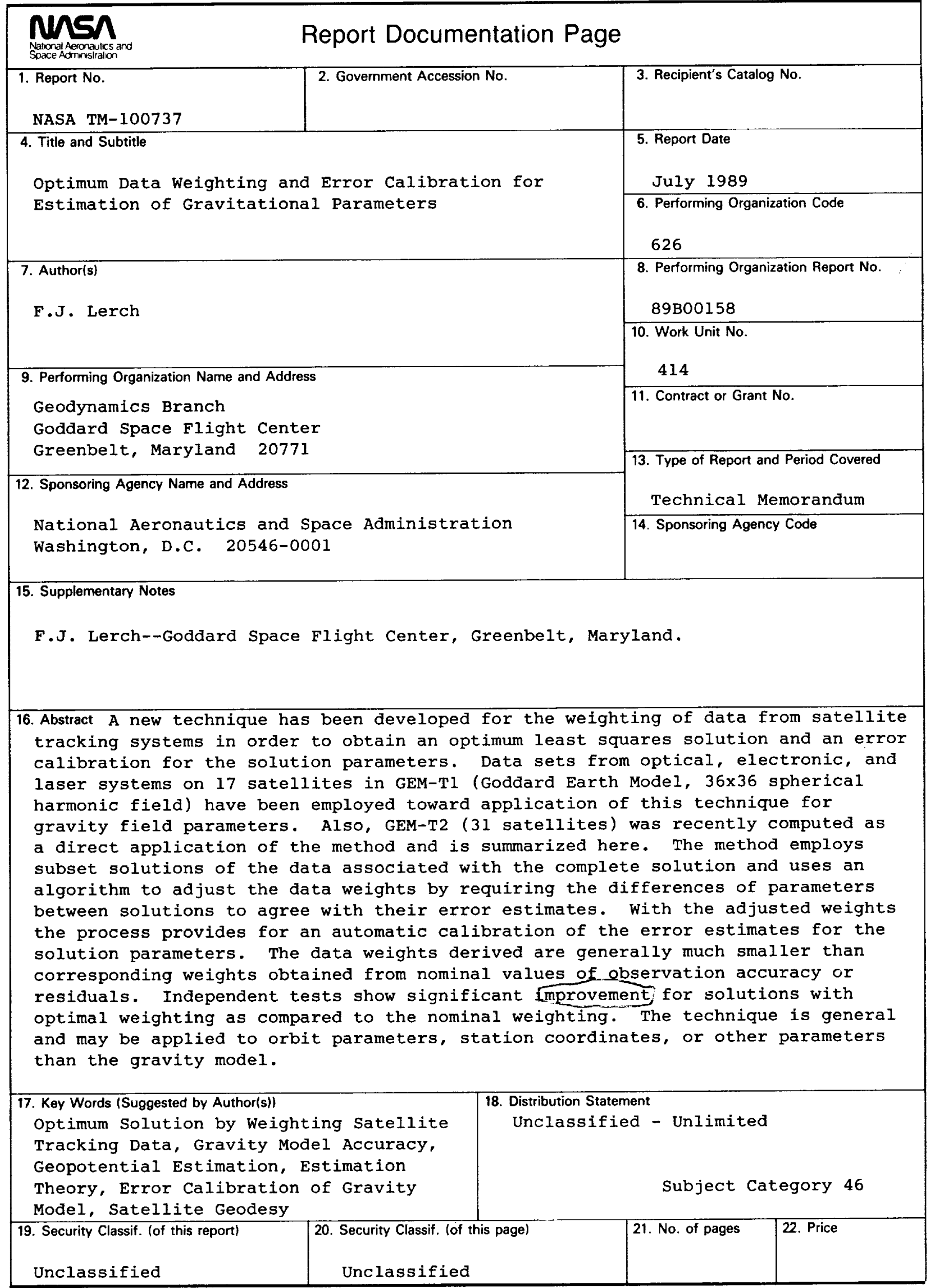




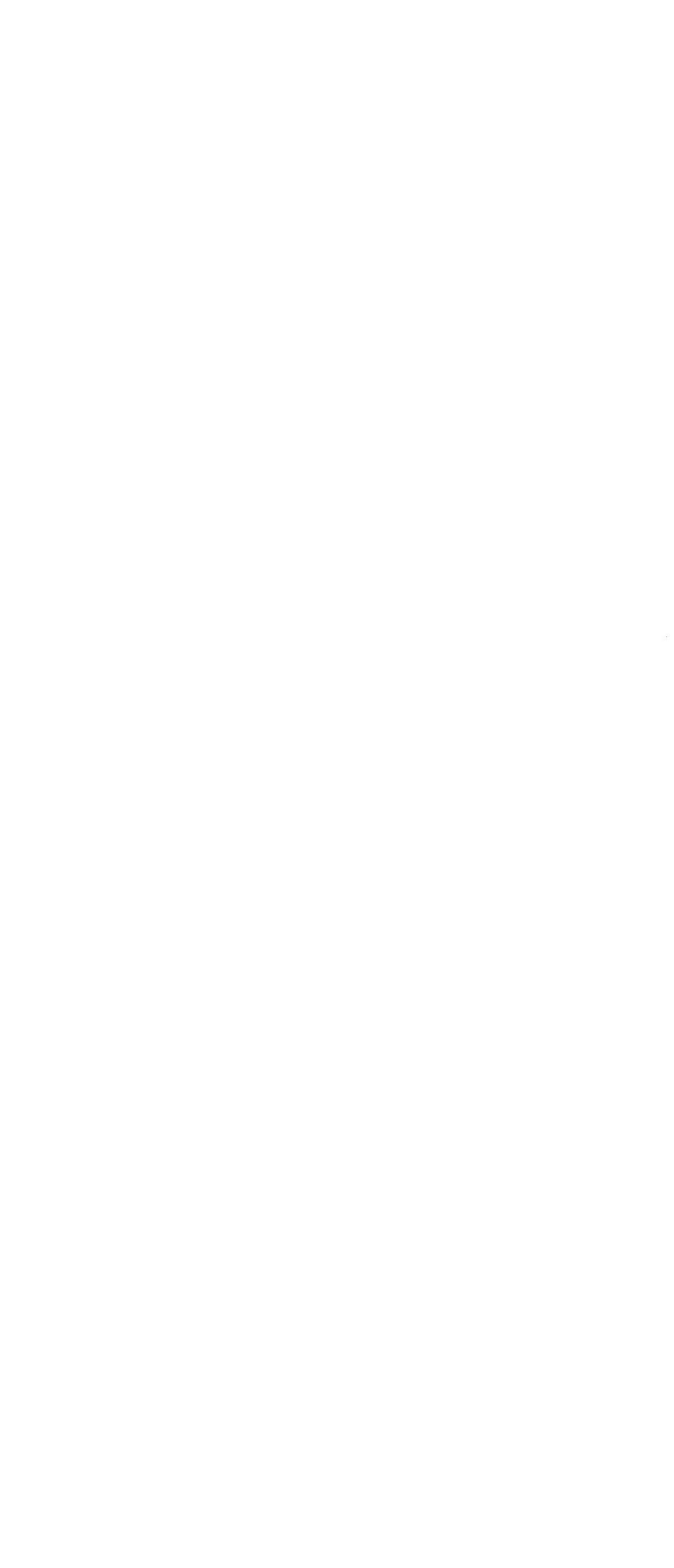

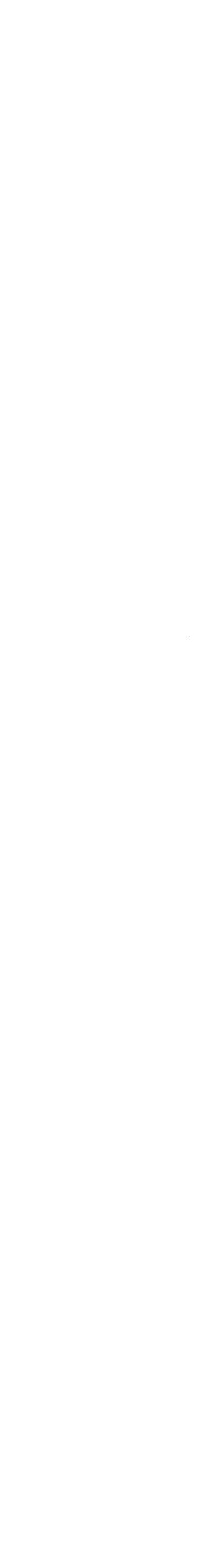

